\title{
Public goods in tourism municipalities: formal analysis, empirical evidence and implications for sustainable development
}

\section{RICARD RIgALL-I-TORRENT AND MOdEST FLUVIÀ}

U niversitat de Girona, Facultat de Ciències Econòmiques i Empresarials, Campus M ontilivi, 17071 Girona, Spain. E-mail: ricard.rigall@udg.edu.

This paper formally analyses the effects that public goods (in a broad sense) have on tourists and private tourism firms. By approaching the tourism product as a bundle of characteristics, the paper shows how the supply of public goods in tourism municipalities positively affects both the tourists' utility functions and the private firms' production functions. Some implications of this fact regarding the sustainability of tourism are discussed. By means of hedonic methods, empirical evidence of location on prices for hotels on Catalonia's coast (Spain) is provided.

Keywords: externalities; local public goods; sustainable development; hedonic prices

Tourists' choice of where to spend their holidays is affected not only by the private supply (the characteristics of hotels, pubs, campsites, or restaurants, for instance) of the different alternatives under their consideration as possible holiday destinations. The characteristics of the municipality or region where the tourism supply lies also play an important role in the final decision: the cl eanliness of the water for swimming, public safety, the approaches to the resort (roads, airports, railways, ports...), or the preservation of the environment matter. Indeed, if tourists have a positive valuation for public goods, then higher quantities of inputs with public good characteristics would bring higher revenues to firms located in jurisdictions with an adequate supply of them. In a sort of virtuous circle, higher revenues would lead (by means of higher tax revenues) to higher levels of public goods feeding back successive waves that would not stop because of diminishing returns (since public goods are nonrival). Since sustainability of the tourism activity depends on the firms' ability to reproduce the inputs entering the production function, a development model based on public inputs, which are not depleted by their use, is more likely to be sustainable than one relying on private inputs. In spite of the importance of the tourism sector to the economies of many countries, there is not a lot

The authors wish to thank J osep Espinet for providing them with data and two anonymous referees for their helpful advice. 
of research which analyses the effects that the existence (or lack) of public services and infrastructures has on the private supply of tourism products.

This paper develops a formal analysis of the effects of public goods on private tourism firms. It is divided into four sections. The first defines tourism goods as bundles of public and private characteristics or attributes and shows the effects of public goods on private tourism supply. The section following discusses some real world implications regarding the sustainability of tourism, which stem from the model. N ext, to check the hypothesis on which the analysis is built, some empirical evidence is presented on the positive effects that location has on hotel prices. Finally, concluding remarks point out the paper's most relevant findings.

\section{Tourism goods as bundles of characteristics}

To analyse the effects of public goods on tourism firms and then obtain implications for sustainable development, it is enlightening to follow the framework in Rosen (1974), Bartik (1987) and Epple (1987). In what follows, it is assumed that a tourism product ${ }^{1}$ can be understood as a bundle (vector) of objectively measured public and private characteristics or attributes (say n). For instance, for a hotel: category (number of stars); services offered (type and characteristics); distance to leisure facilities; or quantity and quality of public goods and services. Thus, the product offered by a hotel, j, can be represented by means of a vector of characteristics

$$
\mathbf{c}^{j}=\left(c_{1}^{j}, c_{2}^{j}, \ldots, c_{n-1}^{j}, z\right),
$$

where $c$ is the measured value of the (private) characteristic, $i$, and $z$ is an index bringing together the different public attributes which characterize the environment where a hotel is located. ${ }^{2} \mathrm{~N}$ ote that since $\mathrm{z}$ is a public good, its level is the same for all tourism businesses located in the same environment. Therefore, two hotels, $m$ and $n$, offer different products whenever $\mathbf{c}^{\mathrm{m}} \neq \mathbf{C}^{n,},{ }^{3}$ that is, whenever any of hotel m's characteristics differ from those of hotel $n$. When the tourism product is sold in a competitive market, then it is reasonable to assume that a unique price exists for each of the characteristics embedded in the final product. Thus, it is possible to define a price vector

$$
p(\mathbf{c})=p\left(c_{1}, c_{2}, \ldots, c_{n-1}, z\right),
$$

which consumers and firms take as given. In a competitive market, tourists choose the product (bundle of public and private characteristics, Equation (1)) which maximizes their utility, taking the price vector (Equation (2)) as given. On the other hand, firms choose their profit maximizing final output's mix of characteristics taking market prices (Equation (2)) and the production technology as given. The market reaches the equilibrium when tourists' and firms' decisions are compatible. The subsections that follow analyse tourists' and firms' decisions in depth, and the resulting market equilibrium.

\section{The decisions of tourists}

It is assumed that tourists get utility from the consumption of a stay in a hotel room in a jurisdiction or municipality and from the consumption of 
other goods, $x .{ }^{4}$ Thus, the utility function for tourist $t$ can be represented as

$$
u^{t}\left(x, c_{1}, c_{2}, \ldots, c_{n-1}, z\right) \text {, }
$$

where $\partial u / \partial x>0, \partial u / \partial c_{i}>0$ and $\partial u / \partial z>0 .{ }^{5}$ Each tourist faces a budget constraint

$$
x+p(\mathbf{c})=m^{t}
$$

where $\mathrm{m}^{\mathrm{t}}$ is tourist t's exogenous income and good $\mathrm{x}$ plays the role of numeraire (so that its price is normalized to 1 ). The Lagrangian for the problem, given by Equations (3) and (4), is

$$
L=u\left(x, c_{1}, c_{2}, \ldots, c_{n-1}, z\right)-\lambda\left(x+p\left(c_{1}, c_{2}, \ldots, c_{n-1}, z\right)-m\right) .
$$

It is important to note that, when deciding where to spend their holidays, tourists are able to choose the quantity of public good embedded in the tourism product purchased. This framework is similar to that proposed by Tiebout (1956), who assumed that individuals 'voted with their feet' when faced with the decision on which bundle of goods and taxes to choose. Hence, $z$ is a decision variable for tourists and the first order conditions for utility maximization $\operatorname{are}^{6}$

$$
\begin{aligned}
& \frac{\partial \mathrm{L}}{\partial \mathrm{x}} \equiv \frac{\partial \mathrm{u}}{\partial \mathrm{x}}-\lambda=0 \\
& \frac{\partial \mathrm{L}}{\partial \mathrm{c}_{1}} \equiv \frac{\partial \mathrm{u}}{\partial \mathrm{c}_{1}}-\lambda \frac{\partial \mathrm{p}}{\partial \mathrm{c}_{1}}=0 \\
& \cdots \\
& \frac{\partial \mathrm{L}}{\partial c_{\mathrm{n}-1}} \equiv \frac{\partial \mathrm{u}}{\partial c_{\mathrm{n}-1}}-\lambda \frac{\partial p}{\partial c_{\mathrm{n}-1}}=0 \\
& \frac{\partial \mathrm{L}}{\partial z} \equiv \frac{\partial u}{\partial z}-\lambda \frac{\partial p}{\partial z}=0 .
\end{aligned}
$$

By reorganizing Equation (6), first order conditions become

$$
\begin{aligned}
& \frac{\partial p}{\partial c_{i}}=\frac{\frac{\partial u}{\partial c_{i}}}{\frac{\partial u}{\partial x}}=M_{R S_{q_{i x}}} \frac{-}{\partial i}=1, \ldots, n-1 \\
& \frac{\partial p}{\partial z}=\frac{\frac{\partial u}{-\underline{z}}}{\partial u} \equiv M^{\prime} \mathrm{RS}_{z x} . \\
& \overline{\partial x}
\end{aligned}
$$


Assuming that the numeraire good, $x$, is money, Equation $(8)^{7}$ shows that a tourist's consumption decision regarding the quantity of public good included in a tourism product is optimal when the amount of money he or she is willing to pay for the last unit of public good consumed (that is, the tourist's marginal willingness to pay, or marginal valuation for the public good) equals the marginal increase in the tourism product's price due to the last unit of public good embedded in that product $(\partial p / \partial z)$. N ote that if the budget constraint were lineal, then $\partial p / \partial z=p$, so that Equation (8) would not differ from the typical conditions for the optimal consumption of goods $\left(\mathrm{RM} \mathrm{S}_{z x}=p_{z} / p_{x}\right)$. Thus, a tourist's willingness to pay for a given bundle of characteristics (taking utility, $u$, and income as given $)^{8}$

$$
\theta\left(c_{1}, \ldots, c_{n-1}, z ; u, m\right)
$$

may be defined from

$$
u\left(m-\theta, c_{1}, \ldots, c_{n-1}, z\right)=u \text {. }
$$

By differentiating Equation (10) with respect to $c_{1}, c_{2} \ldots, c_{n-1}$ and $z$, one obtains ${ }^{9}$

$$
\begin{gathered}
\frac{\partial u}{\partial x} \underbrace{\frac{\partial x}{\partial \theta} \frac{\partial \theta}{\partial c_{i}}}_{=-1}+\frac{\partial u}{\partial c_{i}}=0 \Rightarrow \frac{\partial \theta}{\partial c_{i}}=\frac{\frac{\partial u}{\partial c_{i}}}{\frac{\partial u}{\partial x}}>0 \quad \forall i=1, \ldots, n-1 \\
\frac{\partial u}{\partial x} \underbrace{\frac{\partial x}{\partial \theta}}_{=-1} \frac{\partial \theta}{\partial z}+\frac{\partial u}{\partial z}=0 \Rightarrow \frac{\partial \theta}{\partial z}=\frac{\frac{\partial u}{\partial z}}{\frac{\partial u}{\partial x}}>0,
\end{gathered}
$$

where $\partial \theta / \partial c_{i}$ and $\partial \theta / \partial z$ are, respectively, the tourist's marginal willingness to pay ${ }^{10}$ for the private and public attributes embedded in the marketed tourism product.

Hence, $\theta\left(c_{1}, \ldots, c_{n-1}, z ; a, m\right)$ is the maximum amount a tourist is willing to pay for bundle $\mathbf{c}=\left(c_{1}, c_{2}, \ldots, c_{n-1}, z\right),{ }^{11}$ and the price effectively paid by a tourist in the market for that combination is $p(\mathbf{c})$. Therefore, a tourist maximizes his or her utility when

$$
\theta\left(c_{1}^{*}, c_{2}^{*}, \ldots, c_{n-1}^{*}, z^{*} ; u^{*}, m\right)=p\left(c_{1}, c_{2}, \ldots, c_{n-1}, z\right)
$$

and

$$
\begin{aligned}
& \left.\frac{\partial \theta}{\partial c_{i}}\right|_{\left(c_{1}^{*}, c_{2}^{*}, \ldots, c_{n-1}^{*}, z^{*} ; u^{*}, m\right)}=\left.\frac{\partial p}{\partial c_{i}}\right|_{\left(c_{1}^{*}, c_{2}^{*}, \ldots, c_{n-1}^{*}, z^{*}\right)} \\
& \left.\frac{\partial \theta}{\partial z}\right|_{\left(c_{1}^{*}, c_{2}^{*}, \ldots, c_{n-1}, z^{*} ; u^{*}, m\right)}=\left.\frac{\partial p}{\partial z}\right|_{\left(c_{1}^{*}, c_{2}^{*}, \ldots, c_{n-1} *^{*}, z^{*}\right)}
\end{aligned}
$$

which imply that, at the optimum, a tourist's willingness to pay for a given 


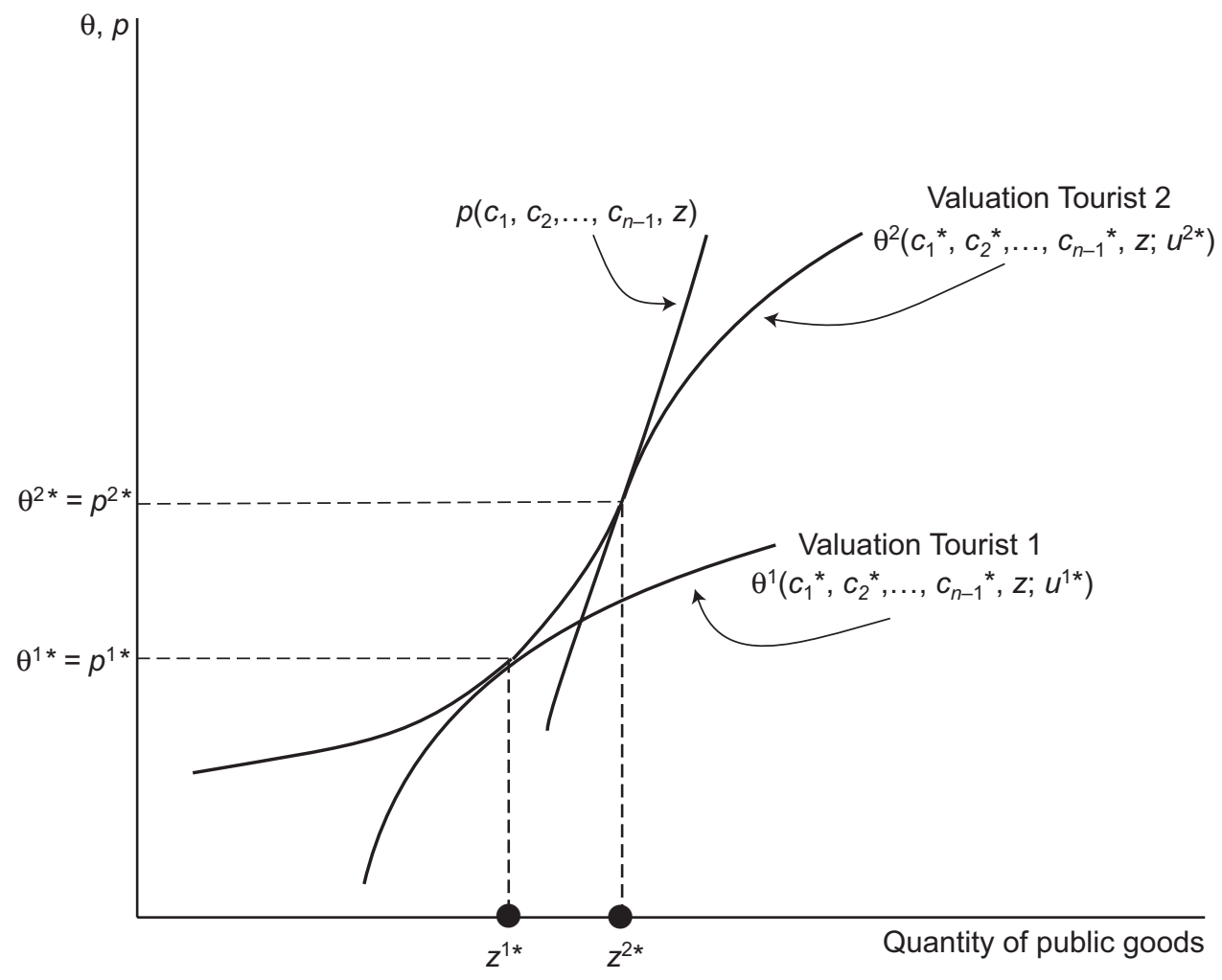

Figure 1. Tourism product purchase decisions by tourists with different valuations for public goods.

product (bundle of characteristics) must be equal to the market price (Equation (12)), and the (marginal) willingness to pay for an additional unit of a given characteristic must be equal to the marginal increase in the price of the final product due to that unit of characteristic (Equation (13)). The graphical representation for two individuals of the analytical results above is shown in Figure 1, where it is assumed that Tourist 2 has higher valuation (willingness to pay) for the public good than Tourist 1 , so that he or she chooses a product (given identical private attributes and characteristics) with a greater amount of public goods. In other words, Tourist 2 chooses to spend his or her holidays in a municipality with a high supply of public goods and, correspondingly, expensive hotels, ${ }^{12}$ whereas Tourist 1 is happy to spend his or her holidays in a tourism resort where the supply of public goods is lower and hotels are cheaper.

\section{The decisions of tourism firms}

Tourism firms must decide upon the quantity and composition of characteristics of the products they wish to market (hotel rooms, in the example above). For firm $j, Q\left(\mathbf{c}^{j}\right)$ denotes the number of units of the tourism product (for instance, the number of hotel rooms) with vector of characteristics $\mathbf{c}^{j}=\left(c_{1}^{j}, c_{2}^{j}, \ldots\right.$, 
$\left.C_{n-1}^{j}, z\right)$. Total costs for each firm, $C(Q, \mathbf{c} ; \beta)$ (where $\beta$ symbolizes factor prices and the parameters that characterize the production function), are obtained from factor cost minimization, subject to the production function. It is assumed that producing an additional hotel room and providing a greater quantity of each of the hotel rooms' characteristics, $c_{i}$, is costly, hence, $\partial C / \partial Q>0$ and $\partial C / \partial c_{i}>0$. It is assumed that fixed costs exist and that, individually, a firm cannot affect the quantity of public good supplied in the municipality in which it is located. Thus, in the short run, each firm would take $z$ as fixed, that is, z. However, in the long run, firms are perfectly mobile, so that they can 'shop around' for the jurisdiction offering the best combination of public goods and taxes. Thus, $z$ is a decision variable for the firm in the long run. Since providing a greater quantity of public goods is costly, municipalities with higher quantities of public goods set higher taxes to cover higher costs of public good provision, so that it is reasonable to assume that $\partial C / \partial z>0$.

In this setting, in the long run, firms maximize

$$
\pi=Q p(\mathbf{c})-C\left(Q, c_{1}, \ldots, c_{n-1}, z\right) \text {. }
$$

$\mathrm{N}$ ote that since firms do not have market power (perfect competition is assumed), $p(\mathbf{c})=p\left(c_{1}, c_{2}, \ldots, c_{n-1}, z\right)$ does not depend on the number of units of output, $Q$. First order conditions ${ }^{13}$ for profit maximization are

$$
\begin{aligned}
& \frac{\partial \pi}{\partial c_{i}} \equiv Q \frac{\partial p}{\partial c_{i}}-\frac{\partial C}{\partial c_{i}}=0 \Rightarrow \frac{\partial p}{\partial c_{i}}=\frac{\frac{\partial C}{\partial c_{i}}}{Q} \quad \forall i=1, \ldots, n-1 \\
& \frac{\partial \pi}{\partial z} \equiv Q \frac{\partial p}{\partial z}-\frac{\partial C}{\partial z}=0 \Rightarrow \frac{\partial p}{\partial z}=\frac{\frac{\partial C}{\partial z}}{Q},
\end{aligned}
$$

and

$$
\frac{\partial \pi}{\partial Q} \equiv p(\mathbf{c})-\frac{\partial C}{\partial Q}=0 \Rightarrow p(\mathbf{c})=\frac{\partial C}{\partial Q}
$$

which imply that each firm is to produce its output by means of a combination of attributes, such that the additional income obtained from the last unit of attribute embedded in the tourism output (for example, hotel room) equals the marginal cost of that attribute per unit of product sold (Equation (15)), and that revenue obtained from the last unit of product sold $(p(\mathbf{c}))$ equals that unit's marginal cost (Equation (16)). ${ }^{14}$ In the same way as for tourists' demand, ${ }^{15}$ it is useful to define a supply function, $\phi\left(c_{1}, c_{2}, \ldots, c_{n-1}, z ; \pi, \beta\right)$, which gives the price at which a hotel is willing to sell a room embedding a number of characteristics or attributes in order to obtain a given level of profit (and considering that the number of units produced is optimal). The supply function $\phi$ is obtained from

$$
\pi=Q \phi-C\left(Q, C_{1}, \ldots, C_{n-1}, z\right),
$$


and

$$
\frac{\partial C}{\partial Q}=\phi
$$

By differentiating Equation (17) with respect to $c_{i}$ and z, one gets, respectively,

$$
\begin{aligned}
& 0=Q \frac{\partial \phi}{\partial c_{i}}-\frac{\partial C}{\partial c_{i}} \Rightarrow \frac{\partial \phi}{\partial c_{i}}=\frac{\frac{\partial C}{\partial c_{i}}}{Q} \quad \forall i=1, \ldots, n-1 \\
& 0=Q \frac{\partial \phi}{\partial z}-\frac{\partial C}{\partial z} \Rightarrow \frac{\partial \phi}{\partial z}=\frac{\frac{\partial C}{\partial z}}{Q},
\end{aligned}
$$

where $\partial \phi / \partial c_{i}$ and $\partial \phi / \partial z$ are, respectively, the prices at which the firm is willing to market an additional unit of public and private attributes as part of a composite tourism product. ${ }^{16}$ The conditions in Equation (19) have the interpretation that the outcome for a firm is optimal when revenue earned because of the inclusion of an additional unit of characteristic in the final product equals the marginal cost of production of that unit of characteristic. Using Equations (18) and (19), Equations (17) and (16) become

$$
\begin{aligned}
& \left.\frac{\partial p}{\partial c_{i}}\right|_{\left(c_{1}^{*}, c_{2}^{*}, \ldots, c_{n-1}^{*}, z^{*}\right)}=\left.\frac{\partial \phi}{\partial c_{i}}\right|_{\left(c_{1}^{*}, c_{2}^{*}, \ldots, c_{n-1}^{*}, z^{*} ; \pi^{*}, \beta\right)} \\
& \left.\frac{\partial p}{\partial z}\right|_{\left(c_{1}^{*}, c_{2}^{*}, \ldots, c_{n-1}^{*}, z^{*}\right)}=\left.\frac{\partial \phi}{\partial z}\right|_{\left(c_{1}^{*}, c_{2}^{*}, \ldots, c_{n-1}^{*}, z^{*} ; \pi^{*}, \beta\right)}
\end{aligned}
$$

and

$$
p\left(c_{1}, c_{2}, \ldots, c_{n-1}, z\right)=\phi\left(c_{1}^{*}, c_{2}^{*}, \ldots, c_{n-1}^{*}, z^{*} ; \pi^{*}, \beta\right),
$$

which may be interpreted in a similar way to, respectively, Equations (12) and (13); for instance, at the optimum, the price at which a firm is willing to supply an additional unit of characteristic must be equal to the variation in the price of the final product due to that additional unit of characteristic (Equation (20)). Besides, the price at which a firm is willing to supply a given bundle of characteristics must be equal to the market price of that bundle.

Figure 2 shows, for two firms ( $A$ and $B$ ), the graphical representation of the optimal decision with respect to the quantity of public goods embedded in the final product. Firm A brings to the market a product with lower quantities of the attribute 'public good' than firm B. This would be the case, for instance, of two firms located in two municipalities, $A$ and $B$. Jurisdiction $A$ is endowed with a low quantity of public goods, $z^{A}$, whereas jurisdiction $B$ supplies a high amount of public goods, $z^{B}$. 


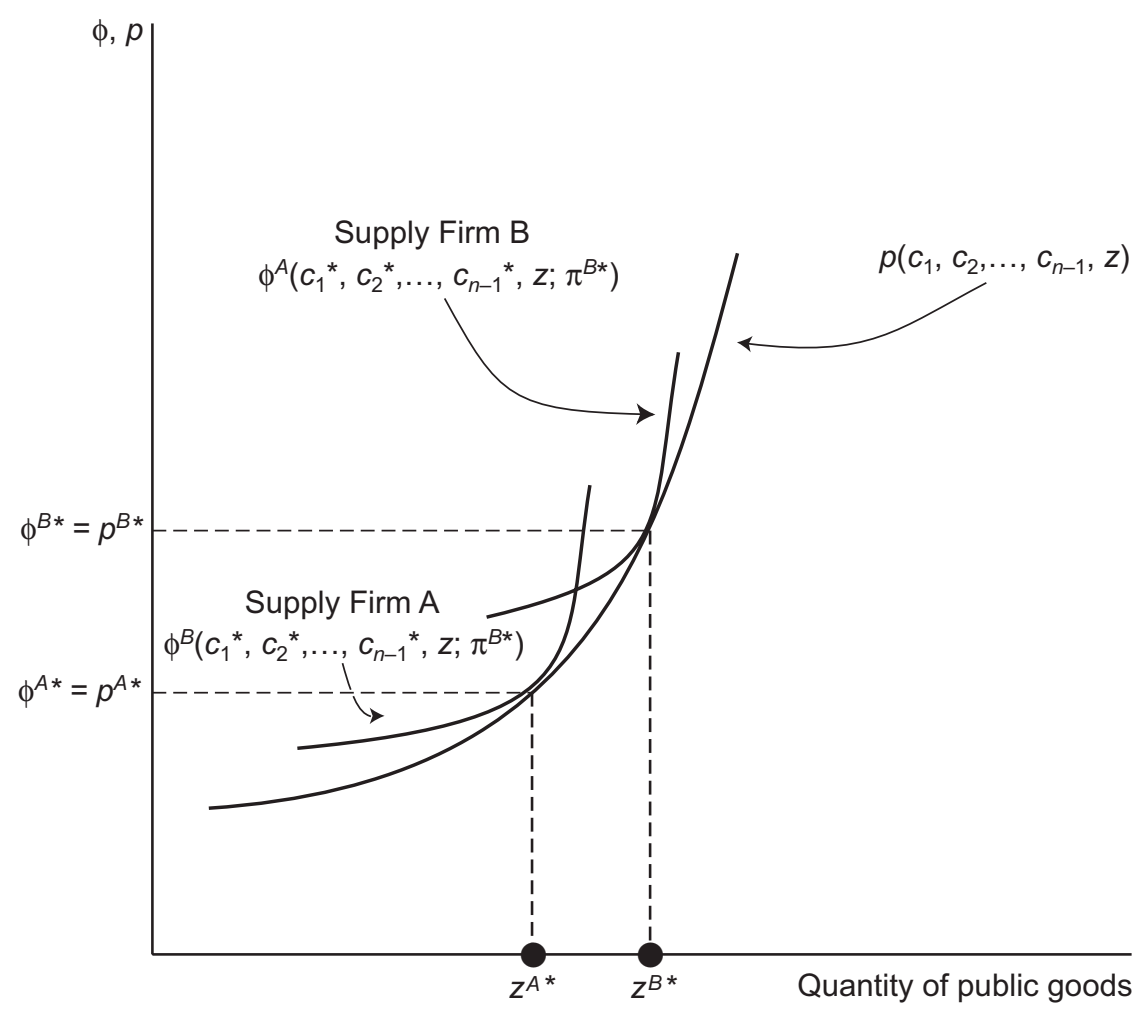

Figure 2. Tourism product supply decisions by firms located in different municipalities.

The equilibrium in the tourism markets

The competitive equilibrium for the economy considered can be defined as the price vector

$$
p^{*}\left(c_{1}, c_{2}, \ldots, c_{n-1}, z\right)
$$

and allocation

$$
\left\{\mathbf{c}^{*}, x^{*}\right\},
$$

such that Equation (23) solves the problems above and markets clear. For a given vector of prices (Equation (22)), the quantity that tourists are willing to buy of a product with a set of characteristics (for instance, the tourists' consumption plan) must be equal to the quantity (of the same product with an identical set of characteristics) that tourism firms are willing to sell (for instance, the firms' production plans). Thus, the equilibrium which brings together the wishes of tourists and firms arises when the valuation functions for the former $(\theta)$ are tangent to the supply functions of the latter $(\phi)$. This means that the equilibrium is reached when the tourists' marginal willingness to pay for an additional unit of characteristic embedded in the tourism product equals the amount of money for which firms are willing to embed the characteristic in the final product. Returning to the hotel example above, in the 


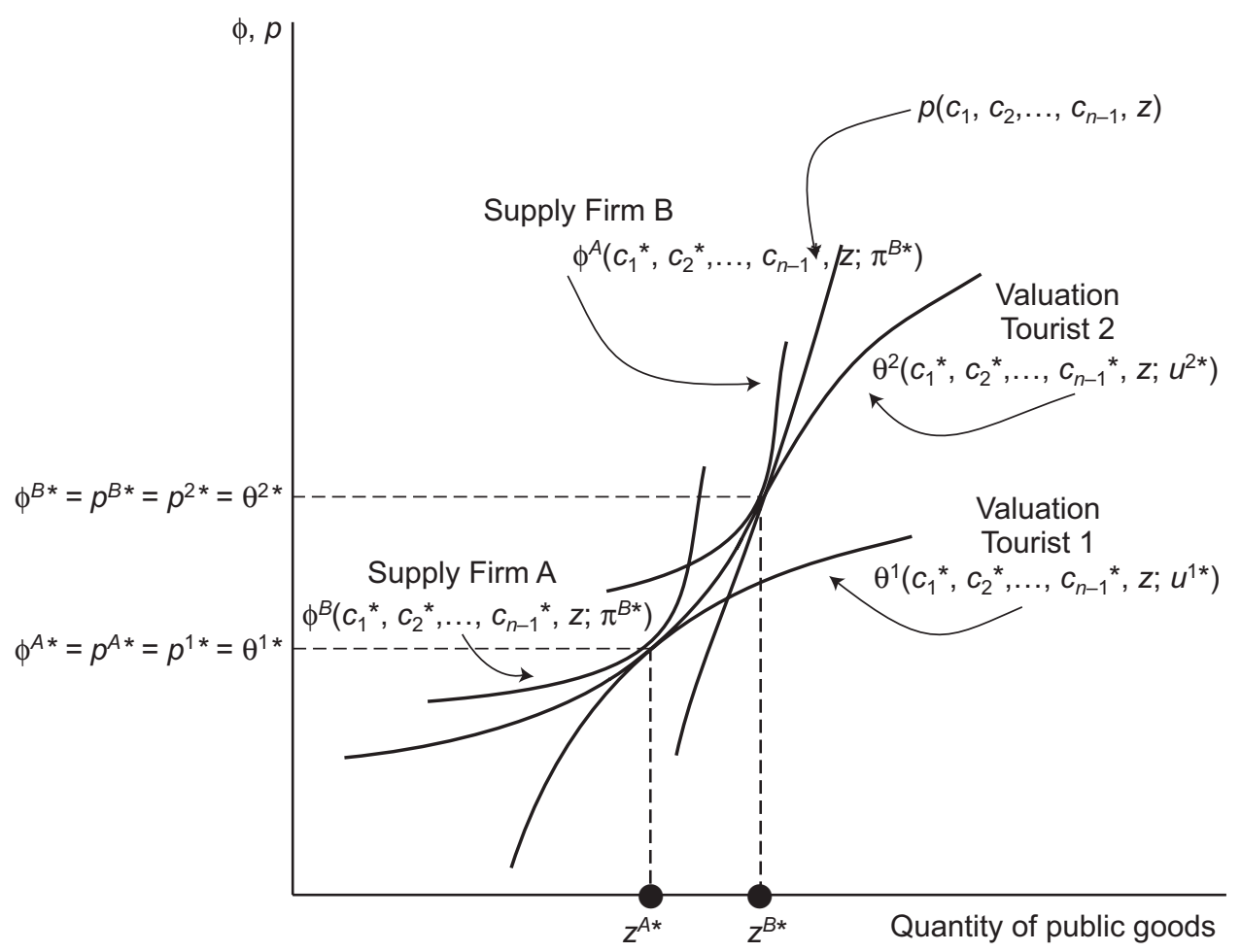

Figure 3. Market equilibrium with two tourists and two firms.

long run (when profits among hotels in different jurisdictions must equalize), tourists with higher valuation for the public good (Type 2) buy the tourism product with a higher quantity of public good (offered by firm B), whereas tourists with lower valuation (Type 1) buy the tourism product bundle with a lower quantity of public goods (offered by firm A). This is shown in Figure $3 .{ }^{17}$

\section{Some implications}

$H$ igher prices do not imply higher profits

In a perfect competition setting such as the one considered here, one should realize that the prices of the tourism supply are, ceteris paribus, higher in those municipalities where higher endowments of public goods exist, not because market power allows firms to set prices above marginal costs, but because quasirents (derived from the environment where tourism supply is located) exist. ${ }^{18}$ This is shown in Figure 4, drawn according to the assumptions made previously. On the demand side, it is assumed that two types of tourists exist, Tourist 1 and Tourist 2,19 so that, given identical private attributes, Tourist 1 has lower valuation for the public good than Tourist $2 .{ }^{20} \mathrm{Hence}$, for a given 


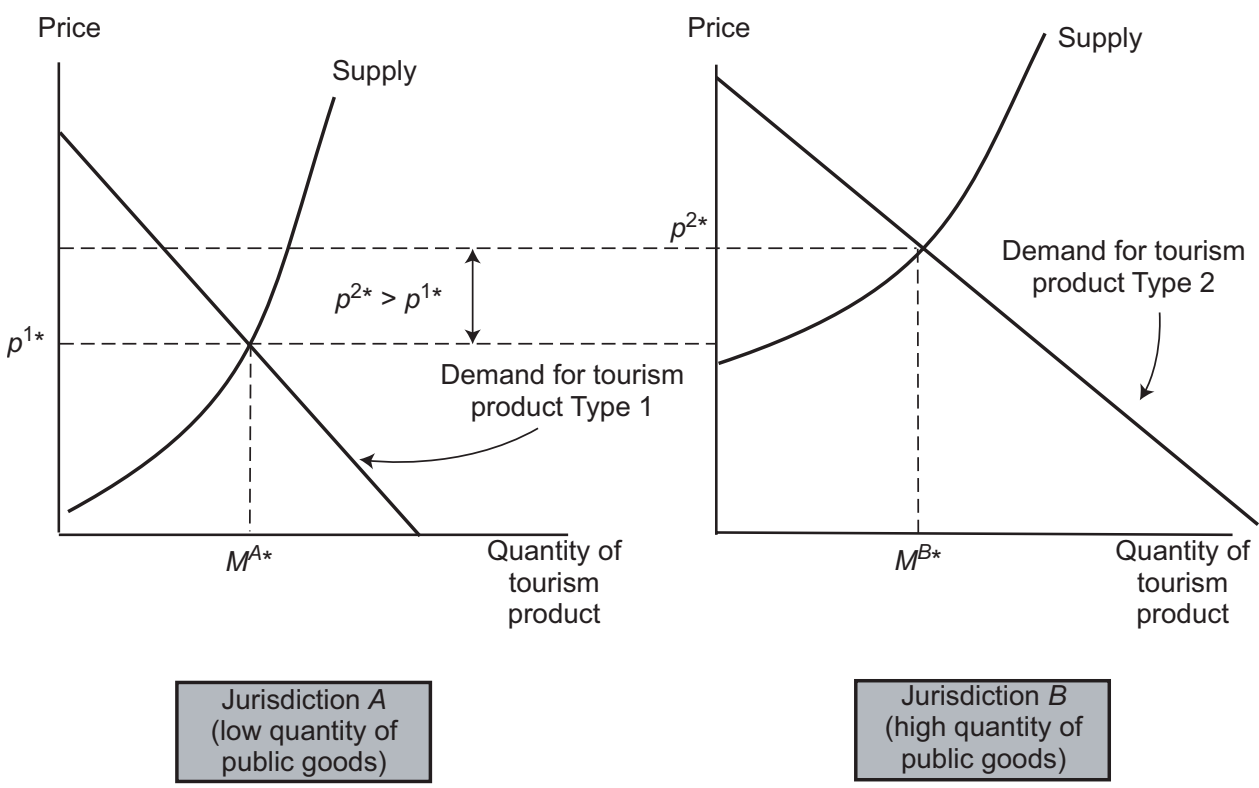

Figure 4. Price differences between tourism products with identical private characteristics but different public attributes in a perfect competition market.

bundle of private attributes embedded in the tourism product, Tourist 2 is willing to pay more to stay at a hotel located (for instance) in a well-preserved environment with a high quantity of public goods. U sing the notation in the second section of this paper

$$
\theta^{2}\left(c_{1}, \tau_{2}, \ldots, \tau_{n-1}, z^{2} ; u^{2}, m^{2}\right)>\theta^{1}\left(c_{1}, c_{2}, \ldots, c_{n-1}, z^{1} ; u^{1}, m^{1}\right)
$$

where $z^{B}>z^{A}$. On the supply side, two municipalities exist with different endowments of quantities and/or qualities of public goods: jurisdiction A (with type A firms) supplies a small quantity of public goods, whereas jurisdiction B (with type B firms) offers a lot of public goods. ${ }^{21,22}$ Both types of firms market a tourism product with identical private characteristics, but different amounts of public goods. Because of quasi-rents, marginal production costs for firms in jurisdiction $B$ are higher than for firms in jurisdiction $A$, since $\partial / \partial z>0$ (as assumed previously) and $z^{B}>z^{A}$ imply $\partial C\left(z^{B}\right) / \partial z>\partial C\left(z^{A}\right) / \partial z$.

According to the notation in the second section of this paper

$$
\phi^{B}\left(c_{1}, \tau_{2}, \ldots, c_{n-1}, z^{B} ; \pi, \beta\right)>\phi^{A}\left(c_{1}, c_{2}, \ldots, c_{n-1}, z^{A} ; \pi, \beta\right)
$$

with $z^{B}>z^{A}$. Thus, as shown in Figure 4 , a hotel located in a run-down environment would be willing to accept a lower price $\left(p^{1 *}\right)$ for the same bundle of private characteristics $\left(c_{1}, c_{2}, \ldots, c_{n-1}\right)$ than a hotel located in a municipality endowed with an excellent natural environment and a high quantity of public goods $\left(p^{2 *}\right)$. In the long run, the equilibrium price for a hotel in jurisdiction $B$ is bound to be higher than in jurisdiction $A$. 


\section{Public goods and sustainability of tourism activity}

The analysis in the previous section al lows some preliminary conclusions on the sustainability of tourism. Although, according to the setting above, differences in the endowments of public goods among jurisdictions do not affect firms' profits in the long run, it is likely that some adverse effects will arise with respect to the sustainability of tourism activity. As a matter of fact, the analysis above is eminently static: it is assumed that inputs are al ways available at given prices and no questions are asked about the sustainability of the economic activity in jurisdictions $A$ and $B$ in the future. $H$ owever, it should be noted that economic activity in jurisdiction A is based on private (rival) goods. This implies that their use leads to their depletion. The sustainability of the tourism activity depends on a firm's ability to reproduce the inputs entering the production function. A development model based on the intensive use of limited (that is, exhaustible) environmental and territorial resources would hardly be sustainable because of depletion and decreasing marginal productivity of capital. For instance, as more hotels are built to accommodate increasing demand, natural and territorial resources become scarcer and, since those re sources are clearly limited (a jurisdiction has fixed boundaries), a limit will be reached at some time in the future. As more capital is employed in a setting in which some resources are fixed, decreasing marginal productivity of capital eventually kicks in.

On the other hand, tourism activity in jurisdiction $B$ is founded on the supply of public goods. As is well known, public goods are non-rival. This implies that they are not exhausted by their use: a unit of public good may be enjoyed by several tourists without losing its properties. Consider, for instance, jurisdiction B's cultural legacy. The tourism supply located in jurisdiction B profits from the municipality's monuments, gastronomy, art and traditions. All these elements build up the jurisdiction's cultural heritage and cannot be cut off from the tourists' experience when they visit that jurisdiction. Besides, a jurisdiction's cultural legacy does not diminish with the number of tourists: ${ }^{23}$ a tourist's enjoyment of a jurisdiction's traditions, art or gastronomy does not preclude other tourists' enjoyment of the same elements. A nother example is the preservation of the environment and the landscape. Once the public good is provided, every tourist is able to enjoy sightseeing a well-preserved environment. Consider al so a jurisdiction's brand image (reputation, prestige): it affects all the firms located there, regardless of a particular firm's brand image. Similar effects occur with public infrastructures and many other elements. Although, in a perfect competition setting, higher prices linked to the supply of public goods do not bring higher profits, they allow firms (by means of higher tax revenues) to offer a product bundle containing a higher quantity and/ or quality of public goods. In a sort of virtuous circle, higher revenues lead to higher levels of public goods feeding back successive waves that do not stop because of diminishing returns (since public goods are non-rival). Therefore, a jurisdiction supporting its growth through public goods is more likely to achieve a development that is sustainable.24

This reasoning is shown in Figure 5 . The broken curve shows the stock of natural and territorial resources available in both jurisdiction $A$ and $B$. The curve in black shows the growth path in jurisdiction A, whose economic 
Consumption of natural

and territorial resources

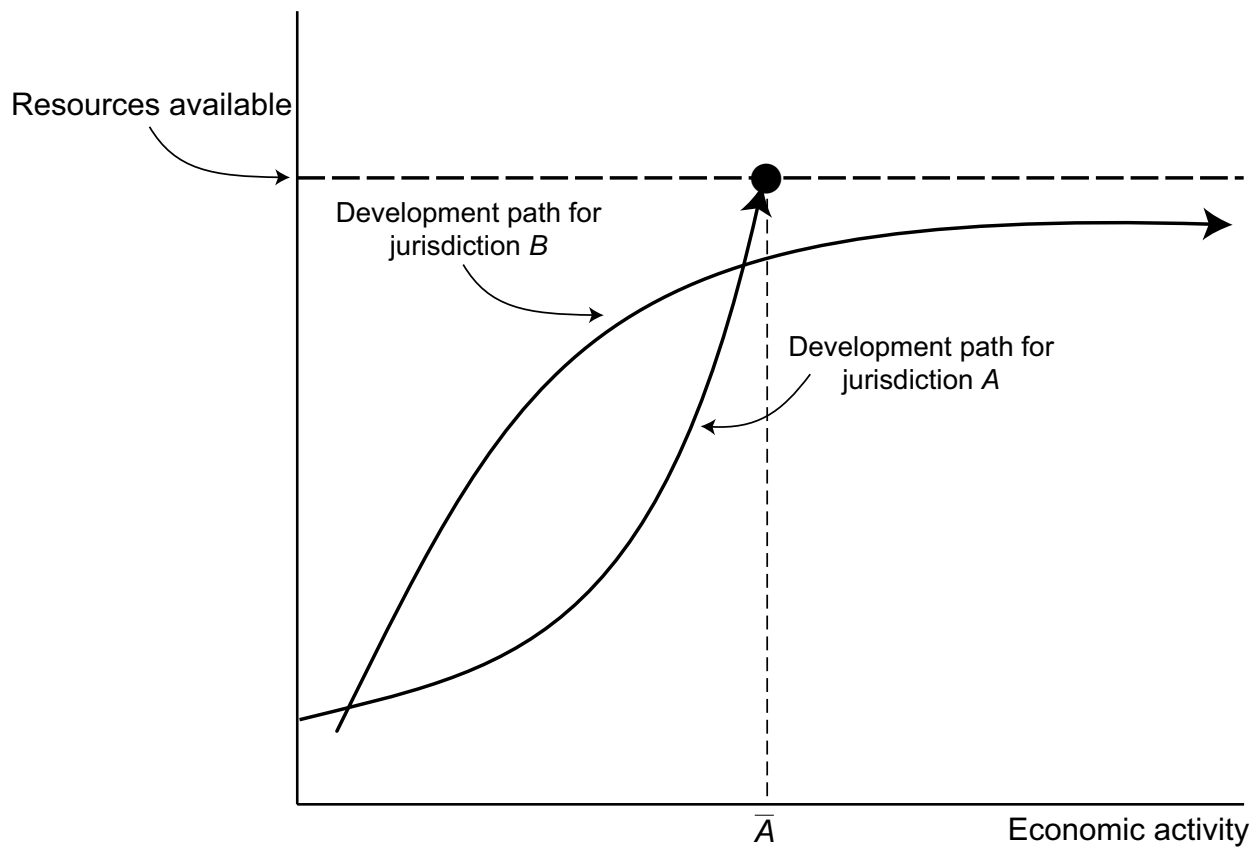

Figure 5. Sustainable (and unsustainable) tourism development with finite resources.

activity ${ }^{25}$ requires the consumption of natural and territorial resources. A tourist model of this kind would hardly be sustainable in the long run since, given a finite endowment of resources, a limit (A) exists from where further increases of economic activity are not possible. The curve in grey shows jurisdiction B's sustainable development path, based on public goods: it is possible to increase economic activity indefinitely without reaching the physical limits set by natural and territorial resources. It should be noted that in a setting where growth is based on public goods, tourism development and the preservation of the environment are complementary goals. Since the environment can be understood as a kind of public good, the preservation of natural resources might allow sustained (and sustainable) economic growth in the long run. A tourism model based on the supply of public goods would thus be able to escape the trade off between economic growth and preservation of the environment.

\section{Empirical evidence}

\section{Preliminaries}

The considerations above would be of little value if they were not supported by empirical evidence. According to the analysis in the earlier section, one would wish to investigate the plausibility of a relationship such as: 


$$
\text { Price }_{i}=g\left(P G_{i}, \mathbf{v} ; \theta\right)
$$

where 'Price' is the price in, say, hotel i, PG denotes the quantity of public goods available in the municipality where hotel $i$ is located, $\mathbf{v}$ is a vector of control variables and $\theta$ is a vector of parameters (to be estimated). In this setting, if the hypothesis that public goods have a positive effect on the prices of hotels were true, then one should expect that

$$
\partial \mathrm{g}(\mathrm{BP}, \mathbf{v} ; \hat{\theta}) .
$$

$\partial B P$

H owever, it is not easy to find homogeneous data regarding the supply of public goods in several municipalities. The analysis that follows is based on RigallI-Torrent (2003). It starts from a database containing information on price (in former Spanish pesetas) and characteristics of double rooms (full board) for a sample of 326 coastal hotels in 15 jurisdictions in Catal onia (in Spain's northeast) for six months of the year 2000 . The analysis proceeds in an indirect way with respect to Equation (26): the jurisdiction where a hotel is located is used as a proxy for the quantity of public goods. In other words, it is assumed that after controlling for the different relevant variables that affect prices, differences in prices among jurisdictions are due to differences in endowments of public goods. Thus, the relationship to be estimated is:

$$
\text { Price }=g \text { (J urisdiction }, \mathbf{v} ; \theta) \text {. }
$$

There is much literature regarding marketing and pricing procedures in the tourism sector. This literature identifies the different relevant characteristics of the hotel product. ${ }^{26}$ Those characteristics are used here as control variables (that is, they conform the vector $\mathbf{v}):^{27}$

- Category (variables: STAR 1, 1-star hotel; STAR2, 2-star hotel; STAR3, 3star hotel; STAR4, 4-star hotel)

- Number of rooms (variable: ROOM)

- $\quad$ Hotel located in front of the beach (variable: $\mathrm{BEACH}$ )

- Room services (variable: ROOMSERV)

- Garden or bal cony (variable: GARDBALC)

- Car park (variable: CARPARK)

- Swimming pool (variable: SW IMPOOL)

- $\quad$ Sports facilities (variable: SPORTS)

- $\quad$ Period of the year (variables: MAY 1, first two weeks in May; MAY 2, second two weeks in May; JUNE1, first two weeks in June; JUNE2, second two weeks in J une; JULY 1, first two weeks in July; JULY 2, second two weeks in July; AUGUST 1, first two weeks in August; AUGUST2, second two weeks in A ugust; SEPTEM BER 1, first two weeks in September; SEPTEM BER 2, second two weeks in September; OCTOBER 1, first two weeks in October; OCTOBER2, second two weeks in October).

It could be argued that, besides the variables above, there are other elements that cause price variations across municipalities, so that, in addition to the supply of public goods, the variable 'jurisdiction' includes the effects that several variables have on price. Failure to control for all relevant variables would 
yield biased estimates. For instance, one could note that the degree of competition might vary systematically among municipalities. H owever, this does not seem plausible for our sample since, in the Catalan coast, generalized entry barriers for new firms do not exist. A nother variable that could affect hotel prices is the distribution channel. O ne could suspect that hotels marketed through big tour operators might charge different prices with respect to, for instance, those hotels which have their own marketing and distribution channels. As a matter of fact, tour operators' bargaining power and different price-setting techniques could give rise to differences in hotel prices. In order to control for this, this paper uses prices published in tour operators' brochures. Besides, if the behaviour and price-setting techniques of tour operators differed among jurisdictions, then differences in tour operators' geographical distribution would systematically affect hotel prices. Although no data are available to check these effects, the results in Espinet (1999) and casual observations indicate that no relevant variations should exist in the sample; that is, the variance in hotel prices is not likely to depend on the geographical location of tour operators. Price differentials could al so be attributed to differences in climatic conditions. This does not apply to the sample, because all municipalities considered are close to each other. Therefore, although the variable 'jurisdiction where a hotel is located' might, in principle, hide several factors which systematically influence hotel prices, great care has been taken in designing the sample of hotels so that problems emerging from omitting relevant variables are minimized.

\section{Estimation}

From the previous considerations, and after several trials, the following specification was estimated by OLS: ${ }^{28}$

$\ln$ PRICE $_{i}=\beta_{0}+\beta_{1}$ BLANES $_{i}+\beta_{2}$ CALELLA $_{i}+\beta_{3}$ CAMBRILS

$+\beta_{4}$ CASFELS $+\beta_{5}$ ESTARTIT $+\beta_{6}$ STFELIU $+\beta_{7}$ MALGRAT

$+\beta_{8}$ PINEDA $+\beta_{9}$ PLATJARO $+\beta_{10}$ ROSES $+\beta_{11} S A L O U+\beta_{12}$ SITGES

$+\beta_{13}$ SUSANNA $+\beta_{14}$ TOSSA $+\beta_{15}$ ROOM $+\beta_{16}$ BEACH $+\beta_{17}$ ROOMSERV

$+\beta_{18}$ GARDBALC $+\beta_{19} C A R P A R K+\beta_{20} S W I M P O O L+\beta_{21}$ SPORTS

$+\beta_{22} M A Y 1+\beta_{23} M A Y 2+\beta_{24} J U N E 1+\beta_{25} J U N E 2+\beta_{26} J U L Y 1+\beta_{27} J U L Y 2$

$+\beta_{28}$ AUGUST $2+\beta_{29}$ SEPTEMBER $1+\beta_{30}$ SEPTEMBER $2+\beta_{31}$ OCTOBER 1

$+\beta_{32}$ OCTOBER $2+\beta_{33} S T A R 1+\beta_{34} S T A R 3+\beta_{35} S T A R 4+u_{i}$

where subscript $i$ denotes the hotel $(i=1 \ldots 279)$ and $u_{i}$ is a random error term, independent and identically distributed (iid), with zero mean and constant variance. The variables that indicate where a hotel is located are: BLANES, Blanes; CALELLA, Calella; CAMBRILS, Cambrils; CASFELS, Castelldefels; ESTARTIT, L'Estartit (jurisdiction: Torroella de M ontgrí); STFELIU, Sant Feliu de Guíxols; MALGRAT, Malgrat de Mar; PIN EDA, Pineda de Mar; PLATJARO, Platja d'A ro (jurisdiction: Castell-Platja d'A ro); ROSES, Roses; SALOU, Salou; SITGES, Sitges; SU SA N N A, Santa Susanna; TOSSA, Tossa de $M$ ar. The left-hand-side variable in logarithms (semi-logarithmic specification) 
Table 1. Empirical evidence of the effects of public goods on hotel prices: hedonic regression.

\begin{tabular}{|c|c|c|c|c|}
\hline Variables & Coefficients & Elasticities & Std. dev. & Significance \\
\hline (Constant) & 8.662 & 8.662 & 0.02 & 0.00 \\
\hline BLAN ES & -0.127 & -0.120 & 0.02 & 0.00 \\
\hline CALELLA & -0.144 & -0.134 & 0.01 & 0.00 \\
\hline CAMBRILS & -0.028 & -0.028 & 0.02 & 0.15 \\
\hline CASFELS & 0.199 & 0.220 & 0.02 & 0.00 \\
\hline ESTARTIT & 0.250 & 0.284 & 0.02 & 0.00 \\
\hline STFELIU & -0.023 & -0.023 & 0.02 & 0.22 \\
\hline MALGRAT & -0.266 & -0.234 & 0.02 & 0.00 \\
\hline PINEDA & -0.165 & -0.152 & 0.02 & 0.00 \\
\hline PLATJARO & 0.110 & 0.116 & 0.02 & 0.00 \\
\hline ROSES & 0.142 & 0.152 & 0.02 & 0.00 \\
\hline SALOU & -0.014 & -0.014 & 0.01 & 0.23 \\
\hline SITGES & 0.342 & 0.408 & 0.02 & 0.00 \\
\hline SUSAN NA & -0.113 & -0.107 & 0.02 & 0.00 \\
\hline TOSSA & 0.155 & 0.167 & 0.02 & 0.00 \\
\hline ROOM & 0.000 & 0.000 & 0.00 & 0.00 \\
\hline $\mathrm{BEACH}$ & 0.090 & 0.094 & 0.01 & 0.00 \\
\hline ROOMSERV & 0.111 & 0.118 & 0.01 & 0.00 \\
\hline GARDBALC & 0.043 & 0.044 & 0.01 & 0.00 \\
\hline CARPARK & 0.065 & 0.067 & 0.01 & 0.00 \\
\hline SW IM POOL & -0.017 & -0.017 & 0.01 & 0.19 \\
\hline SPORTS & 0.076 & 0.079 & 0.01 & 0.00 \\
\hline MAY 1 & -0.768 & -0.536 & 0.02 & 0.00 \\
\hline MAY 2 & -0.719 & -0.513 & 0.02 & 0.00 \\
\hline JUNE1 & -0.628 & -0.466 & 0.02 & 0.00 \\
\hline JUNE2 & -0.483 & -0.383 & 0.02 & 0.00 \\
\hline JULY 1 & -0.238 & -0.211 & 0.02 & 0.00 \\
\hline jULY 2 & -0.105 & -0.099 & 0.02 & 0.00 \\
\hline AUGUST2 & -0.148 & -0.138 & 0.02 & 0.00 \\
\hline SEPTEMBER 1 & -0.439 & -0.355 & 0.02 & 0.00 \\
\hline SEPTEM BER 2 & -0.626 & -0.465 & 0.02 & 0.00 \\
\hline OCTOBER 1 & -0.762 & -0.533 & 0.02 & 0.00 \\
\hline OCTOBER 2 & -0.777 & -0.540 & 0.02 & 0.00 \\
\hline STAR 1 & -0.111 & -0.105 & 0.01 & 0.00 \\
\hline STAR 3 & 0.150 & 0.162 & 0.01 & 0.00 \\
\hline STAR 4 & 0.582 & 0.789 & 0.02 & 0.00 \\
\hline Adjusted $R^{2}$ & 0.806 & & Sign. F & 0.00 \\
\hline
\end{tabular}

$N$ ote: Significant variables at (at least) $95 \%$ of confidence appear in bold.

allows the interpretation of the estimated coefficients as the percentage (after performing the transformation $e^{\beta}-1$ ) of a change in the value of a dummy variable on price. ${ }^{29} \mathrm{No}$ multicollinearity or heteroskedasticity problems were observed.

Table 1 shows the results of estimating Equation (29) with the data in the sample. The column 'Elasticities' shows the estimated coefficients transformed in percentages. The fit of the model is very good $\left(R^{2}=0.806\right)$. Most of the variables are significant. ${ }^{30}$ The coefficients associated to the variables referring 
Table 2. Price differentials among jurisdictions for a hotel with identical private characteristics (index number Lloret de Mar $=100$ ).

$\begin{array}{lr}\text { Jurisdiction } & \text { Index } \\ \text { Sitges } & 140.76 \\ \text { L'Estartit } & 128.40 \\ \text { Castelldefels } & 122.04 \\ \text { Tossa de Mar } & 116.74 \\ \text { Roses } & 115.23 \\ \text { Platja d'Aro } & 111.58 \\ \text { Lloret de Mar } & 100.00 \\ \text { Salou } & 98.60 \\ \text { Sant Feliu de Guíxols } & 97.72 \\ \text { Cambrils } & 97.19 \\ \text { Santa Susanna } & 89.34 \\ \text { Blanes } & 88.04 \\ \text { Calella } & 86.60 \\ \text { Pineda de Mar } & 84.80 \\ \text { Malgrat de Mar } & 76.62\end{array}$

to 'jurisdiction' show the effect of a given municipality on hotel prices: they indicate the price differential (percentage) between two hotels offering identical bundles of private goods (in the same period of the year) but, since they are located in different jurisdictions, distinct public characteristics. From Table 1, it is possible to compute price indices showing the effects of public characteristics on hotel prices in different municipalities. This is shown in Table 2, where Lloret de Mar is the reference, taking a value $100 .{ }^{31} \mathrm{It}$ is important to note that wide differences exist among price levels in different jurisdictions. For instance, the price of a hotel located in the municipality at the top of the ranking is $83.7 \%$ higher than that for a hotel located in the jurisdiction at the bottom of the list. For a given set of private characteristics (category, number of rooms, being located in front of the beach, having room service, garden or bal cony, car park, swimming pool or sports facilities) and period of the year, differences arise which, given the considerations above, can be reasonably attributed to different endowments of public goods (in a broad sense) in distinct municipalities. Therefore, empirical evidence seems to confirm the plausibility of the hypothesis that public goods positively affect private tourism supply.

\section{Concluding remarks}

This paper argues (both theoretically and empirically) that public goods have a positive influence on the supply of private tourism firms: greater endowment of public goods leads to higher prices for tourism goods with otherwise identical private characteristics. In turn, higher prices would lead to higher revenues for those firms located in jurisdictions where greater supply of public goods exists. This is important with regard to the sustainability of tourism. Indeed, although in a perfect competition setting higher prices would not bring higher profits 
in the long run, they would allow (by means of higher tax revenues) firms to offer a product bundle containing higher quantities and/or qualities of public goods. Thus, in a sort of virtuous circle, higher revenues could lead to higher levels of public goods feeding back successive waves of investment and growth that would not stop because of diminishing returns (since public goods are nonrival). At the end of the day, a tourism jurisdiction relying on a tourism model supported by a greater quantity and/or quality of public goods would be able to enjoy a greater growth margin than a jurisdiction relying on a growth model based on the intensive use of rival, limited resources.

\section{Endnotes}

1. Since the data available for the empirical analysis refer to hotels, 'tourism product' in this paper is usually identified with 'hotel product'.

2. The empirical analysis in the section 'Some implications' considers characteristics c as dichotomic. For instance, if $c_{1}$ refers to the availability of a swimming pool in a hotel, then $c_{1}$ takes the value of 1 if the hotel $\mathrm{j}$ offers that kind of facility and 0 otherwise.

3. If two hotels are located in the same environment (which implies identical z), then their outputs will differ if at least one of the values, $c_{i}^{m}$, varies from any of the values, $c_{i}^{n}$.

4. The term, $x$, can be understood as a bundle of different products, each in turn composed of different characteristics.

5. It is assumed that each of the characteristics of a product yields utility to the consumer (that is, there are no 'bads').

6. It is assumed that the price function, $p(\mathbf{c})$, is not too concave, so that first order conditions are necessary and sufficient in order to get a maximum (see Rosen, 1974).

7. The interpretation of Equation (7) is identical, changing 'private characteristic' for 'public good'.

8. Following the notation above, Equation (9) represents the amount of money a tourist with income $\mathrm{m}$ is willing to forego (pay) to be able to enjoy a stay in a hotel with characteristics $\mathbf{c}=\left(c_{1}, c_{2}, \ldots, c_{n-1}, z\right)$.

9. Inequalities follow from the strict concavity of the utility function.

10. In other words, the marginal valuations (or maximum price a consumer is willing to pay) for an additional unit of each attribute.

11. For given levels of utility and income.

12. Remember that the comparison is among hotels with identical private characteristics (which have identical prices in different municipalities because of the perfect competition assumption). Thus, the price of the hotel where Tourist 2 spends his or her holiday must be more expensive than Tourist 1 's, since $p_{z}>0$ and $z^{2}>z^{1}$.

13. It is assumed that first order conditions are both necessary and sufficient, so that a maximum is attained.

14. $N$ ote that, in the short run, the condition obtained from $\partial \pi / \partial z=0$ would yield the quantity of public good wished by a hotel $j, z^{j *}$. H owever, since the decision on the final quantity of public goods provided, $z$, would not depend on hotel j, it would usually be the case that $z^{i *}=z$. Thus, the profit for firm j would normally be lower in the short run.

15. See Equation (9).

16. Again, it is assumed that the conditions for a maximum are satisfied.

17. Throughout the paper, it is assumed that the tourism market is in equilibrium, that is, that no excess demand or supply exists. It could be argued that this assumption does not suit tourism markets, since mismatches between supply and demand abound. However, it should be noted that mismatches arise because adjustment costs are ignored. Once adjustment costs are taken into account, disequilibrium vanishes. See Maddala (1983) for an in-depth analysis of these questions.

18. This varies from the findings of Taylor and Smith (2000), who show that differentiated environmental characteristics allow private firms to set prices above marginal costs, but it is in accordance with the empirical setting considered.

19. It is assumed that there are high numbers of both types of individuals, so that no monopsony exists in the market for the tourism product.

20. See Figure 2. 
21. It is assumed that high numbers of both types of firms exist in both markets, so that no monopoly power is possible.

22. See Figure 3.

23. Although, in some cases, congestion may occur: consider, for instance, tourists visiting a museum.

24. For the sake of concreteness, imagine that the aggregate production function in municipality A at time t is $Y(t)=B(t) \cdot K^{\alpha}(t) \cdot L^{1-\alpha}(t)$, where $Y$ is aggregate product, $B$ is technology, $K$ is capital, $\mathrm{L}$ labour and $\mathrm{B}>0$ and $0<\alpha<1$. This production function shows constant returns to scale and decreasing marginal products for capital and labour. Thus, unless technology changes, per capita growth is limited. The production function for municipality $B$ would be

$$
Y(t)=B(t) \cdot Z^{1-a}(t) \cdot K^{a}(t) \cdot L^{1-a}(t),
$$

where $Z$ is 'public goods'. N ow, since, public goods are non-rival, per capita growth can continue indefinitely. See, for instance, Barro and Sala-i-Martin (1999).

25. Measured, for instance, as the number of tourists attracted or the gross domestic product obtained.

26. See, for instance, Espinet (1999), Espinet and Fluvià (2001) and Espinet et al (2003).

27. All the control variables, except the number of rooms, are dichotomic, taking the value 1 when the condition is satisfied and 0 otherwise.

28. A specification without logarithms was al so carried out. H owever, the fitting obtained was worse than when using logarithms. Anyway, since all variables (except the number of rooms) are dichotomic, the number of easily interpretable al ternative specifications is cl early limited. H ence, no tests based on Box-Cox transformations regarding the functional specification are presented.

29. Remember that prices were originally in Spanish pesetas. The irrevocable conversion rate for the euro vis-à-vis the Spanish peseta is $€ 1=166.386$ Spanish pesetas.

30. As a matter of fact, only the coefficients associated to 'Swimming pool', 'Sant Feliu de Guíxols', 'Cambrils' and 'Salou' are not statistically different from zero.

31. Obviously, it is possible to change the reference by a simple operation without changing the results.

\section{References}

Barro, R.J., and Sala-i-Martin, X. (1999), E conomic G rowth, The MIT Press, Cambridge, MA.

Bartik, T.J. (1987), 'Estimating hedonic demand parameters with single market data: the problems caused by unobserved tastes', R eview of Economics and Statistics, Vol 69, No 1, pp 178-180.

Epple, D. (1987), 'H edonic prices and implicit markets: estimating demand and supply functions for differentiated products', J ournal of Political Economy, Vol 95, No 1, pp 59-80.

Espinet, J.M. (1999), A nàlisi del SPreus al Sector H oteler de la C osta B rava Sud [A nalysis of hotel prices in the south of the Costa Brava], PhD dissertation, Universitat de Girona, Girona.

Espinet, J.M ., and Fluvià, M. (2001), 'U na aproximación a los diferentes precios en el sector hotelero: el ejemplo de la Costa Brava Sur', Cuadernos de Turismo de la U niversidad de M urcia, Vol 7, pp 23-34.

Espinet, J .M., Sáez, M., Coenders, G., and Fluvià, M. (2003), 'The effect on prices of the attributes of holiday hotels: a hedonic prices approach', Tourism Economics, Vol 9, No 2, pp 165-177.

Maddala, G.S. (1983), Limited-D ependent and Qualitative Variables in Econometrics, Cambridge University Press, Cambridge.

Rigall-I-Torrent, R. (2003), H isendes L ocals i Turisme: Tres A ssaigs [M unicipalities and tourism: three essays], PhD dissertation, U niversitat de Girona, Girona.

Rosen, S. (1974), 'H edonic prices and implicit markets: product differentation in pure competition', Journal of Political Economy, Vol 82, pp 34-55.

Taylor, L.O., and Smith, V.K. (2000), 'Environmental amenities as a source of market power', $\underline{\mathrm{L} \text { and }}$ Economics, Vol 76, No 4, pp 550-568.

Tiebout, C.M. (1956), 'A pure theory of Tocal expenditures', J ournal of Political Economy, Vol 64, pp 416- 424. 